\title{
Fabrication Methods for SU-8 Optical Interconnects in Plastic Substrates
}

\author{
Hanan H. Hamid, Thomas Fickenscher, Steven G. O'Keefe, Member, IEEE, \\ and David V. Thiel, Senior Member, IEEE
}

\begin{abstract}
Buried optical interconnects promise high speed interconnections between electronic circuits on circuit boards. Previous attempts have relied on expensive microfabrication technologies and complex optical coupling systems. The circuits in plastic (CiP) manufacturing method has electronic components embedded in a plastic substrate making direct optical coupling possible. Four different machining methods were used to create optical waveguides in polymethyl methacrylate (PMMA) substrate and with SU8 channel, covered with a thin sheet of PMMA. A three-layer milling technique showed least attenuation $(1.17$ and $1.20 \mathrm{~dB} / \mathrm{cm}$ at 1310 and $1550 \mathrm{~nm}$, respectively). The technique shows significant promise for low cost fabrication of CiP with optical interconnects.
\end{abstract}

Index Terms-Circuits in plastic (CiP), CNC milling, hot embossing, optical interconnects, optical waveguides.

Manuscript received October 20, 2013; revised March 25, 2014; accepted April 20, 2014. Date of publication April 25, 2014. This work was supported by the University of Mosul Scholarship through the Iraqi Government.

H. H. Hamid, S. G. O'Keefe, and D. V. Thiel are with the Center for Wireless Monitoring and Applications, School of Engineering, Griffith University, Nathan 4111, Australia (e-mail: hanan.hamid@griffithuni.edu.au; s.okeefe@griffith.edu.au; d.thiel@griffith.edu.au).

T. Fickenscher is with the Department of Electrical Engineering/Helmut Schmidt University, University of the Federal Armed Force Hamburg, Hamburg 22043, Germany (e-mail: thomas.fickenscher@hsu-hh.de).

Color versions of one or more of the figures in this letter are available online at http://ieeexplore.ieee.org.

Digital Object Identifier 10.1109/LPT.2014.2320323 flexible than glass and, thus, the possibility of cracking and separation are avoided.

Many construction methods have been suggested for polymer optical waveguides in circuit boards (e.g. laser ablation, UV lithography, hot embossing, moulding and direct laser writing). Most of these methods create the polymer waveguides in silicon or FR4 board substrates [5]. The waveguide core roughness created during the fabrication phase plays a significant role in the overall waveguide loss.

The objective is to achieve coupling between the optoelectronic devices, which are usually mounted on top of the substrate layer, and the optical waveguides fabricated in a different layer. The optical coupling between layers is achieved using optical components such as micro lenses, micro mirrors and ball lenses. These optical components are both complicated and expensive to fabricate [6], [7].

A simple, inexpensive fabrication technique was reported [8] using a $152.4 \mu \mathrm{m}$ rotary saw to cut the waveguide into a plastic substrate. Direct coupling method was used to couple the light from the emitter to an SU-8 multimode waveguide via a graded index multimode fiber (GI-MMF). The attenuation was $1.66 \mathrm{~dB} / \mathrm{cm}$ and $1.51 \mathrm{~dB} / \mathrm{cm}$ at $1550 \mathrm{~nm}$ and $1310 \mathrm{~nm}$ wavelength, respectively. The main loss factor was attributed to the surface roughness of the waveguide grooves introduced during the machining process. Roughness in the waveguide sidewalls leads to scattering of guided optical wave into the plastic substrate which forms the waveguide cladding.

In this article, four fabrication methods for producing multimode optical waveguides in plastic substrate are reported. The same direct coupling method was used to couple the light to and from the optical channel via multimode optical fibers [8]. The propagation loss for four different path lengths of the channel was used to determine the loss coefficient.

\section{WAVEGUIDE FABRICATION}

All methods were aimed at the construction of a channel with cross-sectional dimensions $0.6 \times 0.6 \mathrm{~mm}^{2}$ in a $3 \mathrm{~mm}$ PMMA substrate refractive index 1.488. At each end, a $0.9 \times 0.9 \mathrm{~mm}^{2}$ fiber groove was machined for external optical fiber coupling as shown in Fig. 1. The external optical fibers were cleaved and then glued into the fiber grooves. Here after, the channel groove was filled with the SU-8 2000.5 photoresist epoxy resin (refractive index 1.577 ). The optical channel was oven-cured for 90 minutes (prebaking at $65^{\circ} \mathrm{C}$ temperature for 15 minutes and post baking at $90^{\circ} \mathrm{C}$ for 60 minutes). 


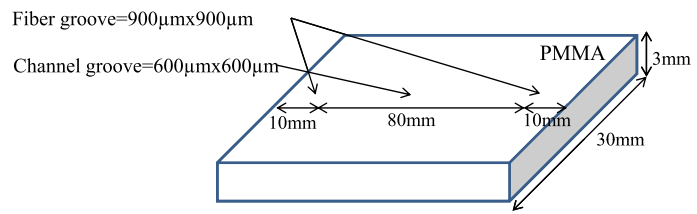

Fig. 1. Standard test bed used for waveguide fabrication and attenuation measurements.

After cooling, the top cladding layer was thermally laminated on the top of the sample. The sample preparation, cleaning and the fibers arrangement and placing as well as the embossing conditions are explained in more detail in [8]. The waveguide groove was fabricated using four different methods: rotary saw, two layer milling, three layer milling and laser cutting.

\section{A. Rotary Saw}

A $152.4 \mu \mathrm{m}$ rotary saw was used to create optical channel grooves in the $3 \mathrm{~mm}$ PMMA substrate [8]. The sidewall and bottom surfaces of the waveguide were found to be not sufficiently smooth and so the path loss in the waveguide was high.

\section{B. CNC Machining}

A CNC milling machine of $\pm 0.005 \mathrm{~mm}$ resolution was used to mill the channel and fiber grooves in the $3 \mathrm{~mm}$ thick PMMA substrate. The sidewall of the channel groove showed less surface roughness than that achieved by the rotary saw method (see Fig. 2). Though the sidewall roughness was not significant, the bottom of the channel groove showed significant machine markings from the $\mathrm{CNC}$ rotary cutter.

\section{Three Layer Milling}

The fabrication of the channel grooves involves two steps: cutting right through the channel structure in a thin PMMA sheet and then hot embossing this sheet on top of a flat substrate sheet. First, a milling machine was used to cut through the fiber grooves $(0.9 \mathrm{~mm}$ width and $10 \mathrm{~mm}$ length $)$ and channel groove $(0.6 \mathrm{~mm}$ width and $80 \mathrm{~mm}$ length) in a $0.6 \mathrm{~mm}$ thick and $120 \mathrm{~mm}$ long PMMA sheet. Hot embossing was used to adhere a $2 \mathrm{~mm}$ thick and $100 \mathrm{~mm}$ long PMMA flat sheet to the thin sheet where the trenches were made. The purpose of the two steps is to get a smooth bottom waveguide surface without the milling marks that were evident in CNC machining process outlined in section II.B. The embossing machine was set at $140^{\circ} \mathrm{C}$ and $130^{\circ} \mathrm{C}$ top and bottom temperature, respectively, and 3 bar pressure was applied for 150 seconds. These conditions were sufficient to ensure excellent adhesion between the two layers and to prevent making air gaps between the two layers next to the channel. This is necessary to prevent the liquid core material from moving in between the two layers.

The optimum setting conditions for the hot embossing machine were chosen after embossing 20 samples at different settings (top and bottom temperatures, pressure, and time).

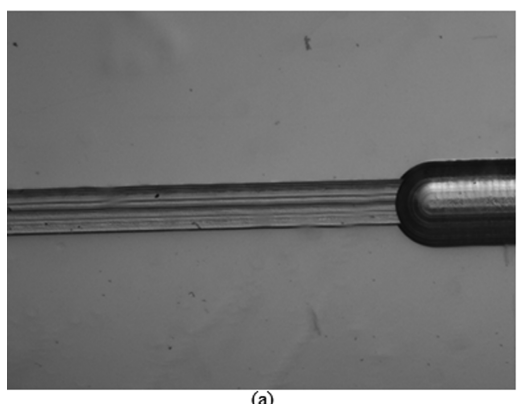

(a)

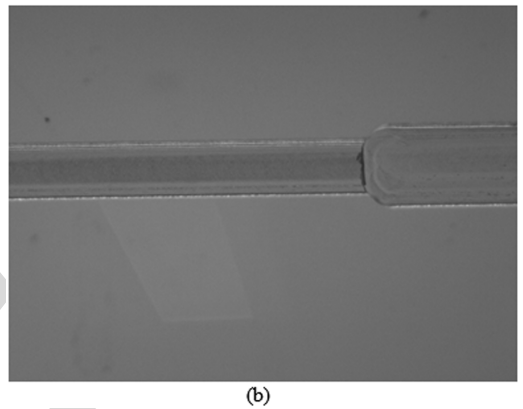

Fig. 2. The channel groove $(600 \mu \mathrm{m}$, left side) and fiber groove (900 $\mu \mathrm{m}$, right side) fabricated in PMMA substrate by using (a) rotary saw and (b) CNC milling machine.

Each time the quality of embossing was tested by a pressure gauge tool. The sample was put inside a pressure container after filling it with a dye. A pressure of 3 bar was applied for 3 hours. After that, the samples were removed and a visual inspection was used to assess the quality of the joint, the formation of a rectangular cross-section channel, and the presence of leaks. The next step was fixing the optical fibers in their grooves using super glue, thus, sealing the two ends of the waveguide. The channel was filled with low-viscosity SU8 and baked. Finally an upper layer of $1 \mathrm{~mm}$ PMMA was hot embossed to seal the optical waveguide and complete the cladding layer. The embossing process was used twice in this method, firstly to attach the layer with trenches to the $2 \mathrm{~mm}$ substrate and secondly for sealing the top of the optical channel (see Fig. 3).

\section{Laser Cutting}

A low cost $\mathrm{CO}_{2}$ laser (wavelength $10.6 \mu \mathrm{m}$ ) was used to cut into a PMMA substrate layer. The control system has a $0.02 \mathrm{~mm}$ step size. This was insufficient to make reasonable smooth waveguide grooves. The cutting by laser was done similarly as with three layer milling method but a laser was used instead of CNC milling machine. This method of cutting is very fast and it is suitable for mass production providing improved cutting accuracy when a laser with smaller step size is used.

\section{Measurements}

Kingfisher laser source (KI7402) emits light at two wavelengths $1310 \mathrm{~nm}$ and $1550 \mathrm{~nm}$. A GI-MMF $(62.5 / 125 \mu \mathrm{m})$ was used to couple the light into the polymer waveguides. The propagation loss in the optical waveguide was measured 


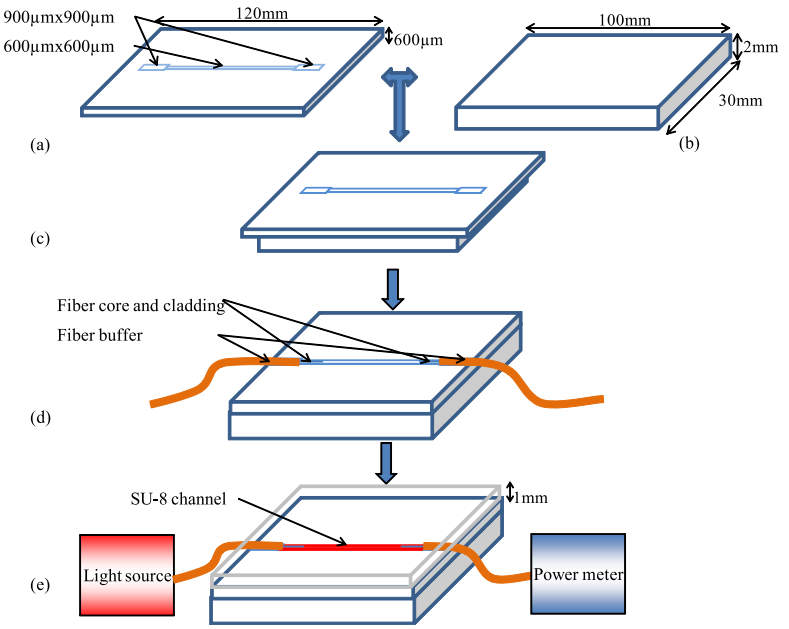

Fig. 3. The fabrication steps of the three layer optical waveguide fabrication method: (a) the desired trenches are made on $0.6 \mathrm{~mm}$ thick clear PMMA substrate; (b) a $2 \mathrm{~mm}$ thick PMMA layer is cleaned and prepared to be the base for the thinner one; (c) the thin substrate with the trenches is placed on top of the substrate and hot embossing is applied to adhere them; (d) the extra side ends of the $0.6 \mathrm{~mm}$ PMMA layer are cut and the channel groove is filled with the SU-8 liquid after the fibers are fixed in their grooves; (e) the channel waveguide is sealed by using hot embossing after the baking step to cure the SU8.

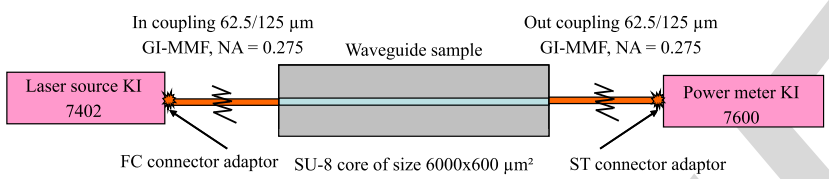

Fig. 4. Block diagram of the transmission test link used to determine the propagation loss in the waveguide sample. The technique requires a laser source, GI-MMF, optical waveguide and power meter.

for the four manufacturing methods: rotary saw, two layer milling, three layer milling and laser cutting. The received optical power was coupled from the waveguide to Kingfisher power meter (KI7600A) via the GI-MMF $(62.5 / 125 \mu \mathrm{m})$ as shown in Fig. 4. The fixed losses which are independent of waveguide length (Fresnel loss, area loss mismatch and numerical aperture mismatch) were calculated theoretically and subtracted from the received optical power and the propagation loss was calculated. The equations are explained in [8]. This measurement method was done for all fabrication techniques except the CNC machining, where the loss was found from the slope of linear fitting of the plotted points. The received power was measured for waveguides of different length instead of using the destructive cut-back method.

\section{RESULTS}

First, the propagation loss of the optical channel made by $\mathrm{CNC}$ milling machine was measured for four different channel lengths $(1.5 \mathrm{~cm}, 3.5 \mathrm{~cm}, 5.5 \mathrm{~cm}$ and $7.5 \mathrm{~cm})$ of the optical channel made by the CNC milling machine. The measurements were recorded for $1310 \mathrm{~nm}$ and $1550 \mathrm{~nm}$ wavelength (see Fig. 5). The waveguide transmission loss was determined from the slope of the linear fitting for the total channel loss versus optical waveguide length. The attenuation was $1.37 \mathrm{~dB} / \mathrm{cm}$ and $1.4 \mathrm{~dB} / \mathrm{cm}$ at $1310 \mathrm{~nm}$ and $1550 \mathrm{~nm}$, respectively.

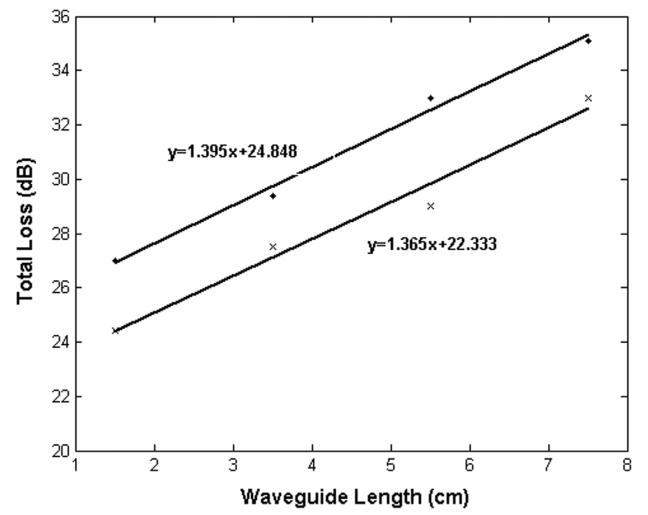

Fig. 5. The total loss for different waveguide lengths fabricated by CNC milling method at two wavelengths $(\times 1310 \mathrm{~nm} ; 1550 \mathrm{~nm})$

TABLE I

COMPARISON OF THE ATtENUATION Loss VALUES AT THE Two WAVELENGTHS FOR THE FOUR DEVELOPED FABRICATION METHODS

\begin{tabular}{ccc}
\hline \hline $\begin{array}{c}\text { Fabrication } \\
\text { method }\end{array}$ & $\begin{array}{c}\text { Attenuation at 1310 } \\
\mathrm{nm} \text { wavelength } \\
(\mathrm{dB} / \mathrm{cm})\end{array}$ & $\begin{array}{c}\text { Attenuation loss at } \\
1550 \mathrm{~nm} \text { wavelength } \\
(\mathrm{dB} / \mathrm{cm})\end{array}$ \\
\hline Rotary saw & 1.51 & 1.66 \\
$\begin{array}{c}\text { CNC marching } \\
\text { Milling right } \\
\text { through } \\
\text { Laser cutting }\end{array}$ & 1.37 & 1.4 \\
\hline \hline
\end{tabular}

The transmission loss at $1550 \mathrm{~nm}$ is a little higher than that at $1310 \mathrm{~nm}$ due to higher material absorption at this wavelength. The mode profile is different which causes an additional offset in coupling. Both slopes exhibit linear behavior (Pearson's correlation coefficient was $\mathrm{R}^{2}=0.97$ and $\mathrm{R}^{2}=0.99$ at $1310 \mathrm{~nm}$ and $1550 \mathrm{~nm}$, respectively).

In a second experiment, optical waveguide samples of $7.5 \mathrm{~cm}$ length were fabricated using the rotary saw cutter, two layer milling, and laser cutting techniques. A comparison (see Table I) was made to obtain the fabrication method with lowest attenuation. It is clear that the propagation loss at $1550 \mathrm{~nm}$ is slightly higher than that at $1310 \mathrm{~nm}$ in all methods.

The results from the saw and laser cutting techniques are similar because the laser cutter used does not provide a channel with small sidewall roughness. It is assumed that this high loss is the result of light scattering at the rough channel walls. The fabrication technique can be improved using a laser control system with smaller step size.

A better result was achieved by the milling and the three layer milling methods. The lowest loss value $(1.17 \mathrm{~dB} / \mathrm{cm}$ and $1.2 \mathrm{~dB} / \mathrm{cm}$ at $1310 \mathrm{~nm}$ and $1550 \mathrm{~nm}$, respectively) was obtained from three layer milling as the scattering from the bottom of the waveguide is reduced when the bottom layer is not milled. In the case of milling right through, the waveguide bottom surface is optically flat and the main source of loss due to surface roughness comes from the waveguide sidewalls. The loss that results solely from the bottom surface roughness of 


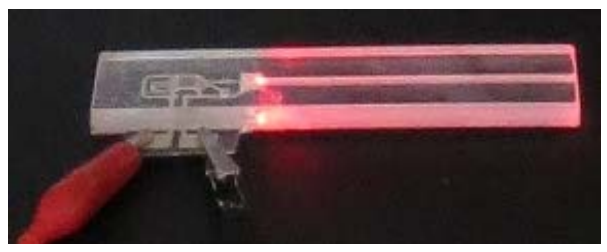

Fig. 6. The complete O-CiP with side view LED at $650 \mathrm{~nm}$ wavelength A timer circuit (LM555 timer IC and passive components) and SU-8 optical channel are formed on $4 \mathrm{~mm}$ thickness PMMA substrate and sealed by $0.5 \mathrm{~mm}$ thickness PMMA sheet with conductive tracks.

TABLE II

Propagation Loss RePorted In SOME RECENT PAPERS FOR OPTICAL WAVEGUIDES FABRICATED B Y MILLING AND LASER Ablation Methods

\begin{tabular}{|c|c|c|c|c|}
\hline $\begin{array}{l}\text { Fabrication } \\
\text { method }\end{array}$ & $\begin{array}{l}\text { Waveguide } \\
\text { dimension }\end{array}$ & Core material & Clad material & $\begin{array}{c}\text { Propagation } \\
\text { loss }\end{array}$ \\
\hline $\begin{array}{c}\text { Direct } \\
\text { milling [9] }\end{array}$ & $\begin{array}{c}100 \times 90 \\
\mu \mathrm{m}^{2}\end{array}$ & PMMA & $\begin{array}{c}\text { Doped } \\
\text { PMMA }(80 \% \\
\text { PMMA and } \\
20 \% \text { SAN) }\end{array}$ & $\begin{array}{c}1 \mathrm{~dB} / \mathrm{cm} \text { at } \\
650 \mathrm{~nm}\end{array}$ \\
\hline $\begin{array}{l}\mathrm{CO} 2 \text { Laser } \\
\text { ablation } \\
{[10]}\end{array}$ & $\begin{array}{c}60 \mu \mathrm{m} \\
\text { depth and } \\
\text { varying } \\
\text { width }\end{array}$ & $\begin{array}{c}\text { Truemode }^{\mathrm{TM}} \\
\text { photopolymer } \\
\text { EXX-core } \\
\text { 37E }\end{array}$ & $\begin{array}{c}\text { Truemode }^{\mathrm{TM}} \\
\text { photopolymer } \\
\text { EXX-clad } \\
277\end{array}$ & $\begin{array}{l}1.3 \pm 0.5 \\
\mathrm{~dB} / \mathrm{cm}\end{array}$ \\
\hline $\begin{array}{l}\text { Laser } \\
\text { ablation } \\
{[5]}\end{array}$ & $45 \times 45 \mu \mathrm{m}^{2}$ & $\begin{array}{c}\text { Truemode }^{\mathrm{TM}} \\
\text { photopolymer } \\
\text { EXX-core } \\
37 \mathrm{E}\end{array}$ & $\begin{array}{c}\text { Truemode }^{\mathrm{TM}} \\
\text { photopolymer } \\
\text { EXX-clad } \\
277\end{array}$ & $\begin{array}{c}1.4 \pm 0.5 \\
\mathrm{~dB} / \mathrm{cm} \text { at } \\
850 \mathrm{~nm}\end{array}$ \\
\hline
\end{tabular}

the samples made by the CNC machining method is about $1.46 \mathrm{~dB}$. It can be determined by comparison of the total loss obtained using the milling right through and the CNC machining method. It can also be seen that sidewall surface roughness of the waveguide fabricated by the laser cutter is significantly higher than that of the three layer milling by $2.7 \mathrm{~dB}$ and $3.3 \mathrm{~dB}$ at $1310 \mathrm{~nm}$ and $1550 \mathrm{~nm}$, respectively. The loss coming from surface roughness using the rotary saw is higher by about $(1.09 \mathrm{~dB}$ and $1.24 \mathrm{~dB}$ at $1310 \mathrm{~nm}$ and $1550 \mathrm{~nm}$, respectively) as compared to the results of the CNC machining method.

In the CiP technology, the circuit components are placed in the substrate layer and silver ink tracks screen printed on the plastic sheet are used to connect the components and seal the complete circuit and the buried optical channel using a thermal press [11]. The optical circuit in plastic (O-CiP) formed in this manner is based on low temperature bonding so the components are not damaged. Optoelectronic and electronic components (e.g. LED, driver circuit, etc.) and the optical channel are integrated in the plastic (see Fig. 6).

\section{Discussion AND CONCLUSIONS}

A $0.6 \times 0.6 \mathrm{~mm}^{2}$ multimode optical interconnect has been fabricated by milling machine, laser cutting, and saw cutter. GI-MMFs were used to couple the light into and out from the optical channel.
Four different methods were used to fabricate the multimode waveguide to determine the method that offers minimum loss. It was found the rotary saw and laser cutter give similar propagation loss $(1.5 \mathrm{~dB} / \mathrm{cm}$ and $1.6 \mathrm{~dB} / \mathrm{cm}$ at $1310 \mathrm{~nm}$ and $1550 \mathrm{~nm}$, respectively) while the two layer milled samples have smoother sidewalls and hence the measured loss was less $(1.37 \mathrm{~dB} / \mathrm{cm}$ and $1.4 \mathrm{~dB} / \mathrm{cm}$ at $1310 \mathrm{~nm}$ and $1550 \mathrm{~nm}$, respectively). The minimum loss was obtained for the three layer milling method: this was $1.17 \mathrm{~dB} / \mathrm{cm}$ and $1.2 \mathrm{~dB} / \mathrm{cm}$ at $1310 \mathrm{~nm}$ and $1550 \mathrm{~nm}$, respectively.

Table II shows the propagation loss from some published results that used milling and laser ablation methods; the milling and ablation processes were done directly on the core layer after spin coating the core material on the substrate layer.

It is seen that the waveguide fabricated in our experiments using $\mathrm{CO}_{2}$ laser has a better performance than reported in [9]. The possibility of using injection molding to form the channels is also under investigation. With the techniques presented no single mode waveguides can be realized due to surface roughness, tolerances and coupling precision requirements.

\section{ACKNOWLEDGEMENTS}

The authors would like to thank T. Nufer from School of Engineering Griffith University for his help in the using of laser machine.

\section{REFERENCES}

[1] D. A. Miller, "Rationale and challenges for optical interconnects to electronic chips," Proc. IEEE, vol. 88, no. 6, pp. 728-749, Jun. 2000.

[2] D. A. Miller, "Optical interconnects to electronic chips," Appl. Opt., vol. 49, no. 25, pp. F59-F70, Sep. 2010.

[3] M. Zhou, "Low-loss polymeric materials for passive waveguide components in fiber optical telecommunication," Opt. Eng., vol. 41, no. 7, pp. 1631-1643, Jul. 2002.

[4] H. Ma, A. Jen, and L. R. Dalton, "Polymer-based optical waveguides: Materials, processing, and devices," Adv. Mater., vol. 14, no. 19, pp. 1339-1365, Oct. 2002.

[5] S. Zakariyah et al., "Fabrication of polymer waveguides by laser ablation using a $355 \mathrm{~nm}$ wavelength Nd:YAG laser," J. Lightw. Technol., vol. 29, no. 23, pp. 3566-3576, Dec. 1, 2011.

[6] C. Berger, B. J. Offrein, and M. Schmatz, "Challenges for the introduction of board-level optical interconnect technology into product development roadmaps," Proc. SPIE, vol. 6124, pp. 144-155, Mar. 2006.

[7] C. Chen et al., " $45^{\circ}$ mirror terminated polymer waveguides on silicon substrates," IEEE Photon. Technol. Lett., vol. 25, no. 2, pp. 151-154, Jan. 15, 2013.

[8] H. Hamid, M. Neeli, T. Fickenscher, S. O'Keefe, and D. Thiel, "Simple low-cost fabrication method of a buried plastic optical waveguide for circuits in plastic interconnects," Microw. Opt. Technol. Lett., vol. 55, no. 8, pp. 1947-1950, Aug. 2013.

[9] D. Snakenborg, G. Perozziello, H. Klank, O. Geschke, and J. P. Kutter, "Direct milling and casting of polymer-based optical waveguides for improved transparency in the visible range," J. Micromech. Microeng., vol. 16, no. 2, pp. 375-381, Feb. 2006.

[10] S. Zakariyah, P. Conway, D. Hutt, K. Wang, and D. Selviah, " $\mathrm{CO}_{2}$ lase micromachining of optical waveguides for interconnection on circuit boards," Opt. Laser. Eng., vol. 50, no. 12, pp. 1752-1756, Dec. 2012.

[11] D. Thiel, M. Neeli, and S. Raj, "Plastic circuit reliability and design for recycling" in Proc. 11th EPTC, Dec. 2009, pp. 858-862.

.

2

255

